\title{
Expression and association of VEGF-Notch pathways in infantile hemangiomas
}

\author{
SHANGBIN LI ${ }^{1}$, GUANGQI XU ${ }^{2}$, FENG GAO $^{2}$, JIANHAI BI ${ }^{2}$ and RAN HUO ${ }^{2}$ \\ Departments of ${ }^{1}$ Healthcare and ${ }^{2}$ Aesthetic, Plastic and Burn Surgery, Shandong Provincial Hospital Affiliated \\ to Shandong University, Jinan, Shandong 250021, P.R. China
}

Received October 12, 2016; Accepted July 31, 2017

DOI: $10.3892 /$ etm.2017.4943

\begin{abstract}
The vascular endothelial growth factor (VEGF) and Notch signaling pathways have been identified to be involved in the neovascularization, and angiogenesis of various tumor types. However, there is little data regarding their roles and association in infantile hemangiomas (IHs). In the present study, the significance and association of the VEGF-VEGF receptor (R)2, and $\delta$ like canonical Notch ligand 4 (Dll4)-Notch1 pathways in different clinical phases of IHs were investigated. Specimens in the proliferating phase $(n=15)$ and involuting phase $(n=12)$ were collected. Quantitative polymerase chain reaction was used to analyze the mRNA levels of VEGF, VEGFR2, Dll4 and Notch1. A further 61 paraffin-embedded IHs (26 in the proliferating group and 35 in the involuting group) specimens were collected to investigate the protein levels of Notch1 and Dll4 using immunohistochemistry, and then analyzed for the association between these factors and microvessel density (MVD). The relative expression levels of VEGF, VEGFR2 and D114 mRNA in the proliferating group were significantly higher compared with that in the involuting group. In addition, the relative levels of Notch1 mRNA were similar in the proliferating and involuting phases. Expression levels of VEGFR2 and D114 mRNA were positively correlated with Notch1 expression in the proliferating IHs. The relative expression of VEGFR mRNA was positively correlated with Dll4 in the proliferating and involuting groups. Immunohistochemical staining demonstrated that Notch1 and Dll4 protein were upregulated in the proliferating IHs compared with the control group. In the proliferating IHs, Notch1 and Dll4 protein expression levels were positively correlated with MVD, while in the involuting phase, only D114 was positively correlated with MVD. The expression levels
\end{abstract}

Correspondence to: Dr Ran Huo, Department of Aesthetic, Plastic and Burn Surgery, Shandong Provincial Hospital Affiliated to Shandong University, 324 Jingwu Road, Jinan, Shandong 250021, P.R. China

E: mail: huoran@medmail.com.cn

Key words: infantile hemangiomas, vascular endothelial growth factor, Notch pathway of related factors in the VEGF and Notch pathways, and the associations among them suggest that they may be involved in the regulation of $\mathrm{IH}$ neovascularization and angiogenesis.

\section{Introduction}

Infantile hemangiomas (IHs) are the most common benign vascular tumors and are characterized by abnormal proliferation of vascular endothelial cells. About $80 \%$ of IHs undergo the clinical phases of proliferation, involution, and completely involution. The proliferating phase is characterized by pathological manifestations of irregular distribution of abnormally proliferating vascular endothelial cells, with no typical vessel-like structures observed. Most of these lesions will undergo an involuting phase, which lasts 7-10 years, with increase of vessel-like structures and decrease of endothelial cell clumps. However, some IHs will leave residual changes after completion of involution, such as telangiectasias, fibro-fatty tissue, scars, excessive atrophic skin and pigment changes. It can be observed in this phase that fat tissue fills the space left by the regression of vascular structures. As can be seen from these clinical phases and pathological features, the development process of IHs is closely related to the abnormal proliferation of endothelial cells. Therefore, the majority of studies on the pathogenesis and treatment of IHs have focused on influential factors of angiogenesis.

With increasing research, more and more pathways have been found to be involved in the neovascularization and angiogenesis of tumors. These pathways interact, influence each other and form a variety of signaling networks. Earlier studies showed that the vascular endothelial growth factor (VEGF) pathway stimulates the proliferation and migration of endothelial cells via activation of a series of downstream signals; among these signals, the Notch pathway plays an important role in the neovascularization and angiogenesis of tumors (1). Moreover, research has shown that the VEGF and Notch pathways interact and regulate each other in the process of angiogenesis and growth in many solid tumors. But few researchers have investigated the expression and relationship of both pathways in the different clinical phases of IHs, especially the impact of the Notch pathway on the transition from proliferating to the involuting phase.

In this paper, we detected the expression of VEGF, VEGFR2, Notch1, and $\delta$ like canonical Notch ligand 4 (Dll4) 
in IHs at different periods by immunohistochemistry and real-time quantitative PCR (Q-PCR), and then analyzed the relationships between these factors and microvessel density (MVD).

\section{Materials and methods}

Specimens. A total of 27 specimens were collected to investigate the levels of mRNAs of VEGF, VEGFR2, Notch1 and Dll4 by Q-PCR. All these fresh specimens were resected from patients ranging in age from 3 months to 6 years old who underwent operations between January 2012 and December 2013 at the Department of Aesthetic, Plastic, and Burn Surgery of the Provincial Hospital Affiliated with Shandong University (Jinan, China). The samples collected at the time of surgery were cut in half; one half was stored in liquid nitrogen at once and kept frozen at $-80^{\circ} \mathrm{C}$ until mRNA testing, while the other half was used for histological analysis to confirm diagnosis of IH. Based on the results of histological analyses and age, the patients were categorized into proliferating group $(n=15)$ or involuting group $(n=12)$ according to the Mulliken classification of IHs. Normal skin samples surrounding the lesions were resected from 10 patients to serve as the control group.

Another 61 paraffin-embedded IHs specimens were collected to investigate the exprexssion of Notch1 and Dll4 by immunohistochemistry. All these specimens were resected from patients ranging in age from 50 days to 6 years old who underwent operations between January 2009 and December 2013 at the Department of Aesthetic, Plastic and Burn Surgery of the Provincial Hospital Affiliated with Shandong University. Diagnoses of IHs were confirmed by histological analyses by the Department of Pathology and divided into proliferating group $(n=26)$ and involuting group $(n=35)$ based on age and pathology results. Normal skin samples surrounding the lesions were resected from 10 patients to serve as the control group.

All procedures conformed to the National Institutes of Health guidelines regarding use of human subjects. This study has been approved by the Medical Ethics Committee of the Provincial Hospital Affiliated with Shandong University.

Quantitative real-time PCR ( $Q$ - $P C R)$. Total RNA was isolated from frozen IHs tissue after grinding with TRIzol reagent (Invitrogen, Carlsbad, CA, USA). cDNA was reverse transcribed from the total RNA using Reverse Transcriptase kit (Toyobo Life Science, Osaka, Japan) in a volume of $10 \mu \mathrm{l}$ (5X reverse transcription buffer $2 \mu \mathrm{l}$, RT primer $0.5 \mu \mathrm{l}$, reverse primer $0.5 \mu \mathrm{l}$, RNA template $1 \mu \mathrm{g}$, MMLV RTase $0.5 \mu \mathrm{l}$, DEPC- $\mathrm{H}_{2} \mathrm{O} 5.5 \mu \mathrm{l}$ ). Quantitative RT-PCR reactions were performed with specific primers designed using the PrimerQuest program by HanBio (Shanghai, China), using SYBR-Green PCR Master Mix (Toyobo Life Science) according to manufacturer instructions. The reactions were completed with 40 cycles in the LightCycler 96 PCR system (Roche Applied Science, Penzberg, Germany) with a sequence of $95^{\circ} \mathrm{C}$ for $3 \mathrm{~min}, 95^{\circ} \mathrm{C}$ for $15 \mathrm{sec}, 60^{\circ} \mathrm{C}$ for $15 \mathrm{sec}$, and $72^{\circ} \mathrm{C}$ for $20 \mathrm{sec}$ in each cycle. Melt curve analysis and agarose gel electrophoresis were carried out to confirm the specificity of the amplified products. The relative concentrations of target
Table I. Primers used to detect VEGF, VEGFR2, Notch1 and Dll4 mRNA.

\begin{tabular}{llc}
\hline \multirow{2}{*}{ Gene } & \multicolumn{1}{c}{ Sequence } & $\begin{array}{l}\text { Size } \\
\text { (bp) }\end{array}$ \\
\hline VEGF & F: TGCCCGCTGCTGTCTAATG & 131 \\
& R: GCGAGTCTGTGTTTTGCAGG & \\
VEGFR2 & F: GCACGATTCCGTCAAGGG & 85 \\
& R: TCTGGCTACTGGTGATGCTGTC & \\
Notch1 & F: CAAGAATGGTGCCAAGTGCC & 273 \\
& R: AAGCAGAGGTAGGCGTTGTC & \\
Dll4 & F: GGGCACCTACTGTGAACTCC & 247 \\
& R: GCTGCCCACAAAGCCATAAG & \\
hGAPDH & F: CGCTCTCTGCTCCTCCTGTT & 81 \\
& R: CCATGGTGTCTGAGCGATGT & \\
\end{tabular}

VEGFR, vascular endothelial growth factor receptor; Dll4, $\delta$ like canonical Notch ligand 4; F, forward; R, reverse.

genes in different tissues were calculated by comparing with the gene expression levels of GAPDH as an internal control using the standard curve and cycle threshold values $(\mathrm{Ct})$. The primers for VEGF, VEGFR2, Notch1 and Dll4 are shown in Table I.

Immunohistochemistry. All paraffin-embedded IHs specimens were sectioned to $4 \mu \mathrm{m}$-thickness and then deparaffined in xylene. After rehydration in grade alcohols, the sections were treated by microwave oven for $15 \mathrm{~min}$ in $0.01 \mathrm{M}$ citrate buffer (pH 6.0) to optimize antigen retrieval. Peroxidase activity was blocked by a $3 \% \mathrm{H}_{2} \mathrm{O}_{2}$ solution for $20 \mathrm{~min}$, and nonspecific binding sites blocked by diluted goat serum for $30 \mathrm{~min}$ at room temperature. Samples were incubated with primary antibodies overnight at $4^{\circ} \mathrm{C}$ in different dilutions following the instructions of our streptomycin avidin-peroxidase kit (SP kit; Zhongshan Co., Ltd., Beijing, China). Incubation with PBS instead of primary antibody was used as a negative control group. All sections were incubated with biotinylated secondary antibody for $20 \mathrm{~min}$ at $37^{\circ} \mathrm{C}$ and then stained with DAB solutions for $5 \mathrm{~min}$. The nuclei were counter-stained with hematoxylin and the samples then dehydrated, mounted and examined.

Measurement of MVD. Positive expression of CD34 protein in the cytoplasm appeared as brown granules in the cells. Three fields with the most dense vascularization were selected under a light microscope at a low magnification (x200), and then MVD were calculated by the number of microvessels. Each CD34 positive cell or one cluster of cells in the forms of strips or tubes was calculated as one microvessel at a magnification of $x 400 . M V D=$ the mean number of the microvessels counted from the three fields.

The immunohistochemistry results were assessed by two different pathologists in the case of unknown clinical data. The random images captured under microscope were analyzed by Image-Pro Plus (IPP6.0) and the average optical density (OD) of each index were calculated. 

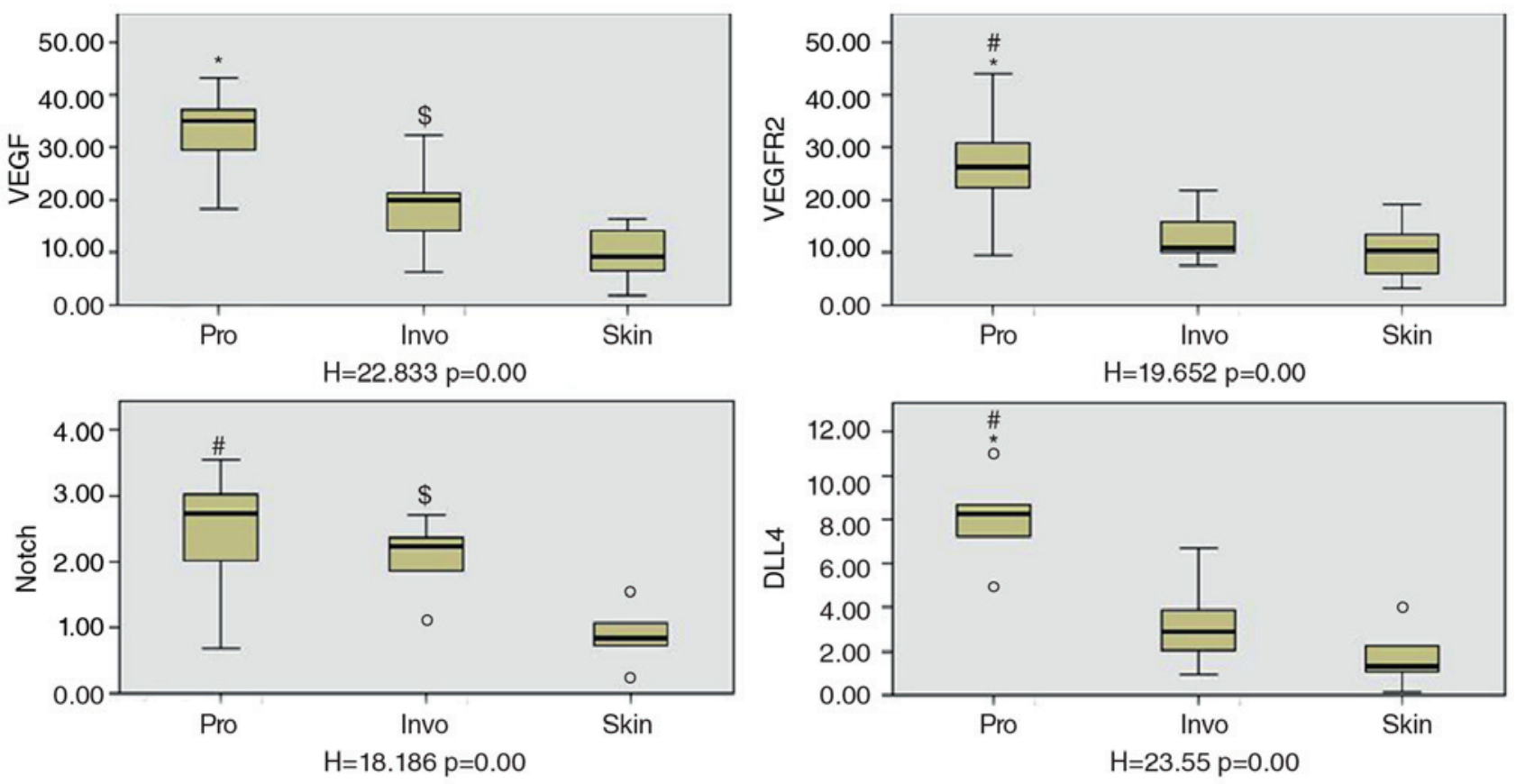

Figure 1. The relative mRNA expression of VEGF, VEGFR2, Notch1, and D114 in different groups ( ${ }^{\#}$ Significant difference between proliferating and involuting

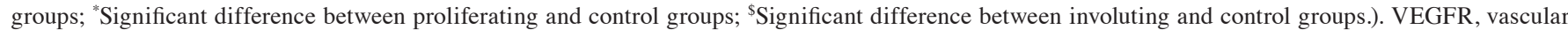
endothelial growth factor receptor; Dll4, $\delta$ like canonical Notch ligand 4; Pro, proliferating; Invo, involuting.

Table II. The average OD and MVD in different groups.

\begin{tabular}{lccc}
\hline & Pro. & Invo. & Control \\
\hline Notch1 & $0.378524 \pm 0.121362$ & $0.338143 \pm 0.090709$ & $0.111431 \pm 0.041648$ \\
Dll4 & $0.309514 \pm 0.108583$ & $0.221769 \pm 0.060432$ & $0.074411 \pm 0.028921$ \\
MVD & $100.69 \pm 22.54$ & $43.35 \pm 13.08$ & $11.67 \pm 7.19$ \\
\hline
\end{tabular}

OD, optical density; MVD, microvessel density; Dll4, $\delta$ like canonical Notch ligand 4; Pro, proliferating; Invo, involuting..

Statistical analysis. All data were presented as the mean \pm standard error (mean $\pm \mathrm{SD}$ ) or median (range), and then analyzed with the SPSS 19.0 software package. ANOVA analysis of variance and Kruskal-Wallis test were carried out to verify the difference among the groups. The Spearman's correlation analysis was applied to verify the relationship between the expression levels of different factors. $\mathrm{P}<0.05$ was considered statistically significant.

\section{Results}

Q-PCR shows that the relative quantity of VEGF mRNA was higher in the proliferating group than in the other groups, and that VEGF mRNA expression was also significantly higher in the involuting group than in the control group $(\mathrm{H}=22.833$, $\mathrm{P}=0.00$ ). Expression of VEGFR2 mRNA was also higher in the proliferating group than in the other groups $(\mathrm{H}=19.652$, $\mathrm{P}=0.00$ ), but there was no significant difference between the involuting and control groups. Notch1 mRNA levels were similar in the proliferating and involuting phases, both of which showed higher levels of Notch1 mRNA than the control group $(\mathrm{H}=18.186, \mathrm{P}=0.00)$. Dll4 mRNA expression was higher in the proliferating group than in the involuting IHs and normal skin $(\mathrm{H}=23.55, \mathrm{P}=0.00)$ (Fig. 1).

We can conclude by the results of Spearman correlation analysis that the relative expression of VEGFR2 mRNA was positively correlated with Notch1 expression in the proliferating IHs $(\mathrm{r}=0.654, \mathrm{P}=0.008)$. VEGF and D114 expression was also positively correlated in proliferating IHs $(r=0.520$, $\mathrm{P}=0.038$ ). In addition, Dll4 is correlated positively with Notch1 in the proliferating IHs $(\mathrm{r}=0.592, \mathrm{P}=0.020)$. In the involuting phase, there were not any significant relations among these factors except for the positive relationship between VEGF and Dl14 (r=0.601, P=0.039) (Fig. 2).

We used immunohistochemical staining to analyze protein expression levels in IHs. Average OD of immunohistochemical staining showed that Notch1 and Dll4 proteins were upregulated in the proliferating IHs compared to the control group. Dll4 protein expression was highest in the proliferating phase $(\mathrm{P}<0.01)$, while Notch1 protein expression was similar in the proliferating and involuting phases $(\mathrm{P}>0.05)$. MVD in proliferating IHs was $100.69 \pm 22.54,43.35 \pm 13.08$ in the involuting group, and $11.67 \pm 7.19$ in normal skin; these differences were statistically significant (Figs. 3 and 4 and Table II). 
A

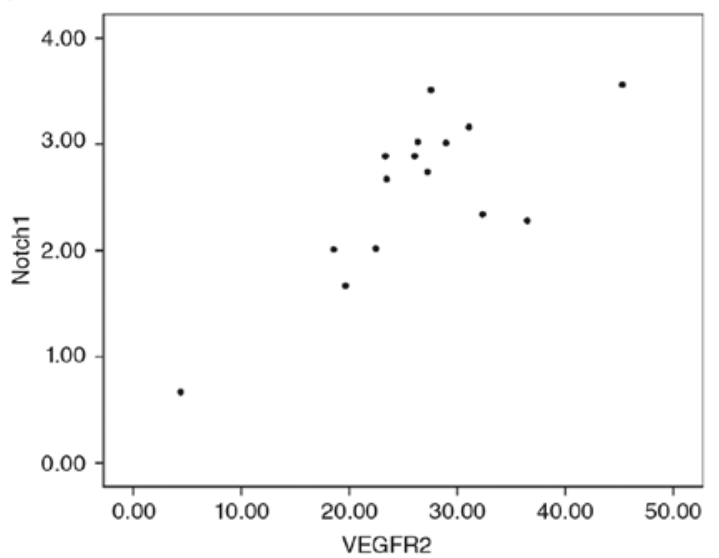

c

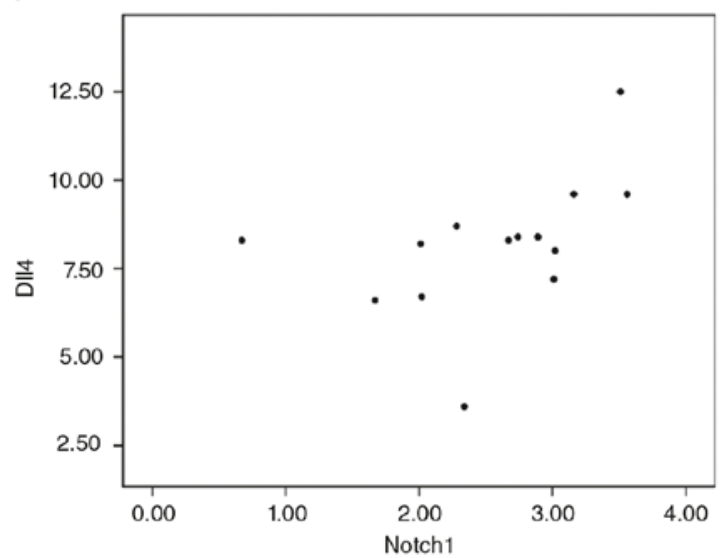

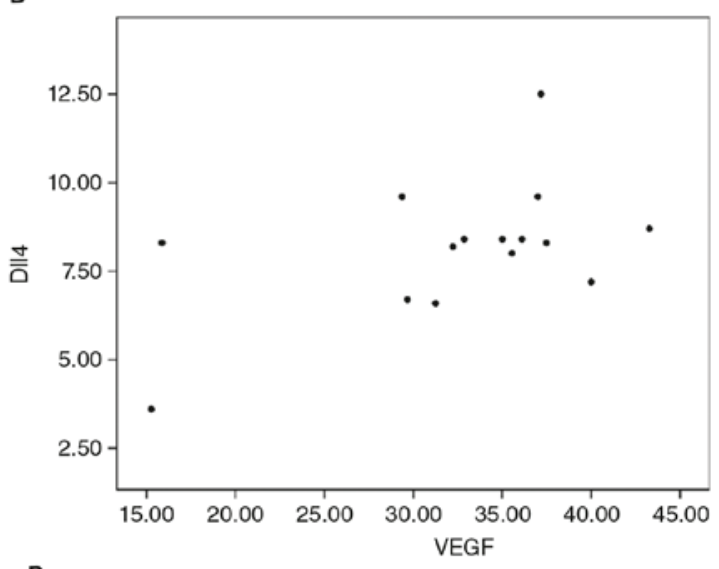

D

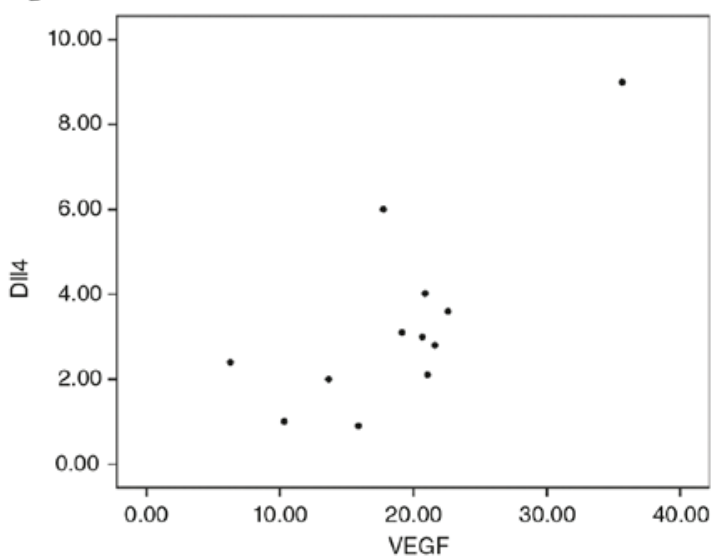

Figure 2. The correlation between relative expression of molecules in IHs. (A) Expression of VEGFR2 mRNA was positively correlated with Notch1 in the proliferating IHs ( $\mathrm{r}=0.654, \mathrm{P}=0.008)$; (B) expression of Dll4 mRNA was positively correlated with VEGF in the proliferating IHs ( $\mathrm{r}=0.520$, $\mathrm{P}=0.038$ ); (C) expression of D114 mRNA was positively correlated with Notch1 in the proliferating IHs ( $\mathrm{r}=0.592, \mathrm{P}=0.020)$; (D) Expression of D114 mRNA was positively correlated with VEGF in the involuting IHs $(\mathrm{r}=0.601, \mathrm{P}=0.039)$. IHs, infantile hemangiomas; VEGFR, vascular endothelial growth factor receptor; Dl14, $\delta$ like canonical Notch ligand 4.

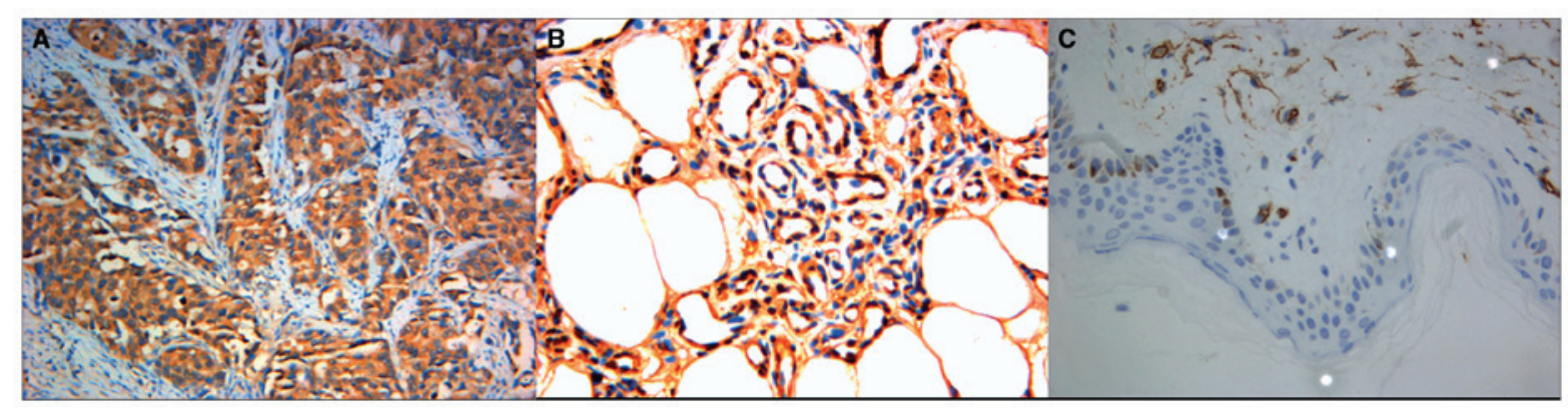

Figure 3. Immunohistochemistry staining of Notch1 (x40 magnification). (A) Proliferating group; (B) involuting group; (C) control group.

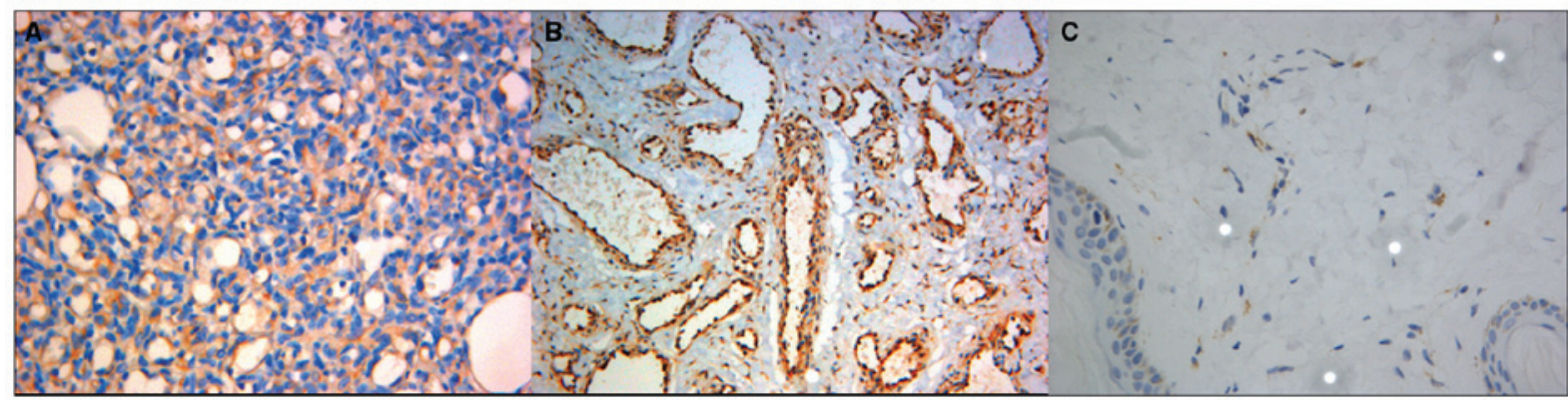

Figure 4. Immunohistochemistry staining of D114 (x40 magnification). (A) Proliferating group; (B) involuting group; (C) control group. D114, $\delta$ like canonical Notch ligand 4. 
A

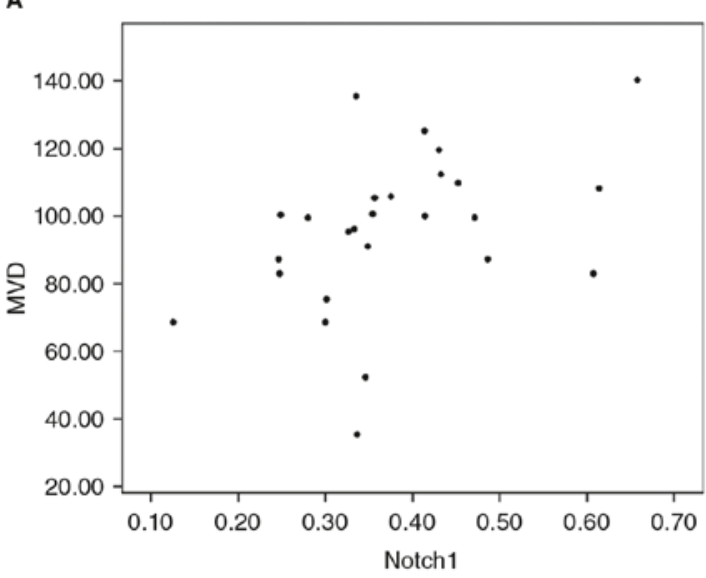

C

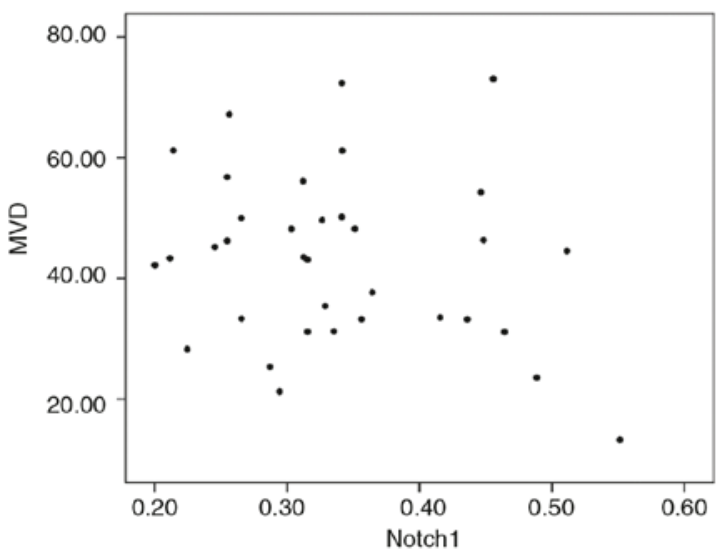

B

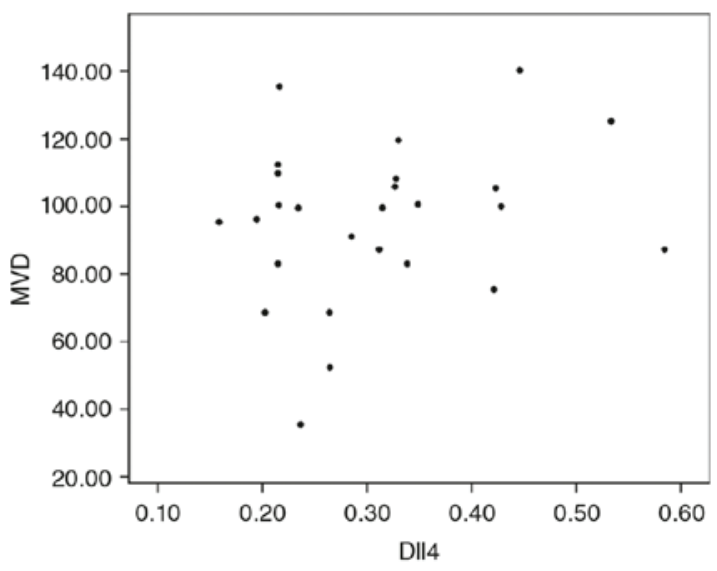

D

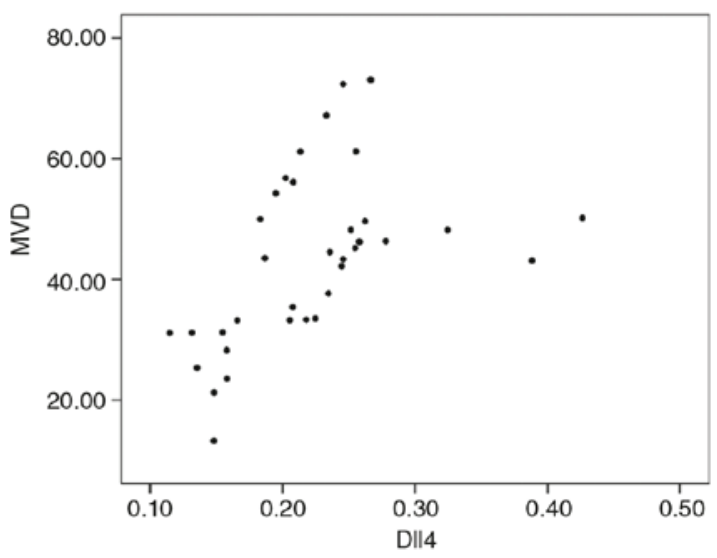

Figure 5. Correlations between the average OD of D114 and Notch1 and MVD in IHs. (A) The ODs of Notch1 was positively correlated with MVD in the proliferating IHs ( $\mathrm{r}=0.429, \mathrm{P}=0.029)$; (B) the ODs of Dl14 was positively correlated with MVD in the proliferating IHs $(\mathrm{r}=0.464, \mathrm{P}=0.017)$; (C) there was no significant correlation between Notch1 and MVD in the involuting IHs ( $r=0.215, P=0.214)$; (D) the ODs of Dll4 was positively correlated with MVD in the incolution IHs ( $\mathrm{r}=0.494, \mathrm{P}=0.003)$. OD, optical density; Dll4, $\delta$ like canonical Notch ligand 4; MVD, microvessel density; IHs, infantile hemangiomas.

In the proliferating IHs, the average ODs of Notch1 and D114 were positively correlated with MVD $(\mathrm{P}<0.05)$. In the involuting phase, Dll4 was also positively correlated with MVD, but there was no significant correlation between Notch1 and MVD (Fig. 5).

\section{Discussion}

Recent studies have focused on the factors impacting neovascularization and angiogenesis in IHs, because the abnormal proliferation of vascular endothelial cells in the tissue of IHs has shown that the proliferation and growth of these tumors are closely related with these processes (2). Neovascularization and angiogenesis are complicated processes co-regulated by cell factors in the extracellular microenvironment and involving many different signaling pathways. Of these pathways, the VEGF and Notch signaling pathways take an important position (3-5). Currently, treatments for IHs include surgery, drugs, radionuclides and laser treatment. Drug treatments have undergone rapid development and are a first choice for IHs, especially glucocorticoids and $\beta$-blockers, although the mechanism of these drugs is still not entirely clear. According to current research, application of glucocorticoids and $\beta$-blockers can repress the proliferation of endothelial cells, and thus the density of the microvessels and growth of the tumors $(6,7)$.
Since therapy of IHs can depend on inhibition of proliferation of endothelial cells and new formation of microvessels, and since the VEGF and Notch pathways appear to play important roles in the processes of neovascularization and angiogenesis, it is of significant interest to investigate the expression of these factors and analyze the relationships among them.

Numerous studies have shown that the VEGF family not only has a crucial impact on the tumorigenesis, development and invasion of many solid tumors such as gastrointestinal cancer, urinary cancer, nervous system tumors, but that VEGF signaling is also significant to the pathogenesis and prognosis of tumors in the blood and lymphatic system (8). VEGF-A is the ligand most involved in VEGFR-mediated angiogenesis and it can promote the differentiation of vascular progenitor cells into vascular endothelial cells (9). Among the receptors, VEGFR1 and VEGFR2 are mainly expressed on the cytomembrane of endothelial cells and take part in the processes of angiogenesis. VEGFR2 is the main mediator of the biological effect of VEGF, and VEGFR1 negatively regulates VEGR2 by competitive binding with ligand (9). In our study, we have found that the expression of VEGF and VEGFR2 were significantly higher in the proliferating group of IHs than in the involuting group and control group. This suggests that the VEGF-VEGFR2 pathway might play an important role in the neovascularization and angiogenesis of IHs. 
The Notch family consists of a group of transmembrane protein receptors can be found in almost every organ and tissue in invertebrate and vertebrate animals (10). Signals are transferred along the pathway by a combination of different ligands and receptors to regulate the proliferation, migration, and apoptosis of almost all cells in the body. The specific receptor Notch1 and ligand Dll4 have been found expressed mainly in vascular endothelial cells, and have been identified as crucial factors in the proliferation and differentiation of these cells (11). In a recent study, Dll4 was found expressed mainly in tip cells rather than stalk cells in new blood vessels, and was identified as a vital factor in the conversion of tip cells to stalk cells, a process critical for maintaining extension and maturation of new vessels (12). In a mouse model of embryo neovascularization, knockout or mutation of Dll4/Notch genes led to early death of embryos due to dysfunction of the newly formed vascular system (13-15). In this paper, we show that expression of Notch1 and Dl14 in proliferating phase IHs was elevated compared to the control group, and that both Notch1 and Dl14 protein expression positively correlated with MVD. Our findings indicate that the expression of Dl14 and Notch1 promote angiogenesis in the proliferating phase of IHs. The expression level of Notch1 in the involuting phase was not significantly different from that in the proliferating phase, even though Dl14 expression was decreased in the involuting phase relative to the proliferating phase. This suggests that the Notch1 receptor might have another important role in the involuting phase of IHs by binding to different ligands.

Numerous studies have established VEGF as the most important cytokine in the proliferation of endothelial cells and new formation of microvessels, and as a connecting link between many other signaling pathways. A study carried out by Hainaud et al (16) showed that VEGF-mediated upregulation of DLL4 and stimulation of Notch can lead in turn to upregulation of EphrinB2 and downregulation of EphB4, both of which are downstream components of the of the Notch pathway. However, this effect of VEGF on EphrinB2 was not observed in tumor models when Notch signals were blocked (17). Furthermore, it has been also confirmed in many experiments in vivo and in vitro that VEGF can upregulate the expression of Jagged1, Dll1, Notch1 and Notch4 (18-21). However, according to other studies, overexpression of Dll4 or Notch significantly decreases expression of VEGFR2, in turn decreasing the biologic effects of VEGF-A on the proliferation and migration of endothelial cells (22). Stimulation of Dll4-Notch signals can also lead to upregulation of VEGFR1 and impairment of ERK activation of VEGF in human umbilical vein endothelial cells (HUVECs) and reduction of vessel sprout length in a model of 3D tubulogenesis (23). Together, current data shows that the Notch pathway seems to play a different role from the VEGF pathway in neovascularization and angiogenesis, and that there is a complex, co-regulating relationship between the Notch and VEGF pathways. In IHs the proliferating phase, we have observed that expression of VEGFR2 was positively correlated with Notch1 expression, and also that expression of VEGF was positively correlated with Dl14. These data confirm that Dl14 and Notch1 may be downstream of the VEGF pathway. While Dl14 protein expression was positively correlated with MVD in both proliferating and involuting IHs, we believe that Dll4 and Notch1 might be expressed mainly in the endothelial cells which form microvessels and play vital roles in tumor progression. Although we see synchronous expression of Dl14 and Notch with VEGR and VEGFR2, the precise nature of the interaction between the Notch and VEGF pathways remains uncertain.

In conclusion, this paper provides an overview and new data useful to confirm the relationship between VEGF-VEGFR2 and Dll4-Notch1 pathways. These findings also show that the Dl14-Notch1 pathway might play a key role in the new formation of microvessels and maintenance of neovascularization and angiogenesis in IHs. Interventions targeting the Dll4-Notch1 pathway might provide a new strategy for the development of drugs to treat IHs.

\section{References}

1. Kerbel RS: Tumor angiogenesis. N Engl J Med 358: 2039-2049, 2008.

2. Yu Y, Flint AF, Mulliken JB, Wu JK and Bischoff J: Endothelial progenitor cells in infantile hemangioma. Blood 103: 1373-1375, 2004.

3. Zhang J, Ye J, Ma D, Liu N, Wu H, Yu S, Sun X, Tse W and Ji C: Cross-talk between leukemic and endothelial cells promotes angiogenesis by VEGF activation of the Notch/Dll4 pathway. Carcinogenesis 34: 667-677, 2013.

4. Boscolo E and Bischoff J: Vasculogenesis in infantile hemangioma. Angiogenesis 12: 197-207, 2009.

5. Phng LK and Gerhardt H: Angiogenesis: A team effort coordinated by notch. Dev Cell 16: 196-208, 2009.

6. Greenberger S, Boscolo E, Adini I, Mulliken JB and Bischoff J: Corticosteroid suppression of VEGF-A in infantile hemangioma-derived stem cells. N Engl J Med 362: 1005-1013, 2010.

7. Annabi B, Lachambre MP, Plouffe K, Moumdjian R and Béliveau R: Propranolol adrenergic blockade inhibits human brain endothelial cells tubulogenesis and matrix metalloproteinase-9 secretion. Pharmacol Res 60: 438-445, 2009.

8. Guo JH, Zhu X, Li XT and Yang RJ: Impact of serum vascular endothelial growth factor on prognosis in patients with unresectable hepatocellular carcinoma after transarterial chemoembolization. Chin J Cancer Res 24: 36-43, 2012.

9. Guo B, Liu Y, Tan X and Cen H: Prognostic significance of vascular endothelial growth factor expression in adult patients with acute myeloid leukemia: A meta-analysis. Leuk Lymphoma 54: 1418-1425, 2013.

10. Lai EC: Notch signaling: Control of cell communication and cell fate. Development 131: 965-973, 2004.

11. Neufeld G, Cohen T, Gengrinovitch S and Poltorak Z: Vascular endothelial grow th factor (VEGF) and its receptors. FASEB J 13: 9-22, 1999.

12. Hofmann JJ and Luisa Iruela-Arispe M: Notch expression patterns in the retina: An eye on receptor-ligand distribution during angiogenesis. Gene Expr Patterns 7: 461-470, 2007.

13. Gale NW, Dominguez MG, Noguera I, Pan L, Hughes V, Valenzuela DM, Murphy AJ, Adams NC, Lin HC, Holash J, et al: Haploinsufficiency of delta-like 4 ligand results in embryonic lethality due to major defects in arterial and vascular development. Proc Natl Acad Sci USA 101: 15949-15954, 2004.

14. Xue Y, Gao X, Lindsell CE, Norton CR, Chang B, Hicks C, Gendron-Maguire M, Rand EB, Weinmaster G and Gridley T: Embryonic lethality and vascular defects in mice lacking the Notch ligand Jagged1. Hum Mol Genet 8: 723-730, 1999.

15. Roca $\mathrm{C}$ and Adams RH: Regulation of vascular morphogenesis by Notch signaling. Genes Dev 21: 2511-2524, 2007.

16. Hainaud P, Contrerès JO, Villemain A, Liu LX, Plouët J, Tobelem G and Dupuy E: The role of the vascular endothelial growth factor-Delta-like 4 ligand/Notch4-ephrin B2 cascade in tumor vessel remodeling and endothelial cell functions. Cancer Res 66: 8501-8510, 2006.

17. Lawson ND, Vogel AM and Weinstein BM: Sonic hedgehog and vascular endothelial growth factor act upstream of the Notch pathway during arterial endothelial differentiation. Dev Cell 3: 127-136, 2002. 
18. Zeng Q, Li S, Chepeha DB, Giordano TJ, Li J, Zhang H, Polverini PJ, Nor J, Kitajewski J and Wang CY: Crosstalk between tumor and endothelial cells promotes tumor angiogenesis by MAPK activation of Notch signaling. Cancer Cell 8: 13-23, 2005.

19. Li JL and Harris AL: Crosstalk of VEGF and Notch pathways in tumour angiogenesis: Therapeutic implications. Front Biosci (Landmark Ed) 14: 3094-3110, 2009.

20. Liu ZJ, Shirakawa T, Li Y, Soma A, Oka M, Dotto GP, Fairman RM, Velazquez OC and Herlyn M: Regulation of Notch1 and D114 by vascular endothelial growth factor in arterial endothelial cells: Implications for modulating arteriogenesis and angiogenesis. Mol Cell Biol 23: 14-25, 2003.
21. Ridgway J, Zhang G, Wu Y, Stawicki S, Liang WC, Chanthery Y, Kowalski J, Watts RJ, Callahan C, Kasman I, et al: Inhibition of Dl14 signalling inhibits tumour growth by deregulating angiogenesis. Nature 444: 1083-1087, 2006.

22. Williams CK, Li JL, Murga M, Harris AL and Tosato G: Up-regulation of the Notch ligand Delta-like 4 inhibits VEGF-induced endothelial cell function. Blood 107: 931-939, 2006.

23. Harrington LS, Sainson RC, Williams CK, Taylor JM, Shi W, $\mathrm{Li}$ JL and Harris AL: Regulation of multiple angiogenic pathways by Dll4 and Notch in human umbilical vein endothelial cells. Microvasc Res 75: 144-154, 2008. 